\title{
PRINCIPAIS PROTOZOÁRIOS ENTÉRICOS OPORTUNISTAS ASSOCIADOS À AIDS: CRYPTOSPORIDIUM PARVUM, ISOSPORA BELLI, CYCLOSPORA CAYETANENSIS E MICROSPORIDIA
}

\author{
MAIN OPPORTUNISTIC ENTERIC PROTOZOA RELATED TO AIDS: CRYPTOSPORIDIUM PARVUM, \\ ISOSPORA BELLI, CYCLOSPORA CAYETANENSIS AND MICROSPORIDIA
}

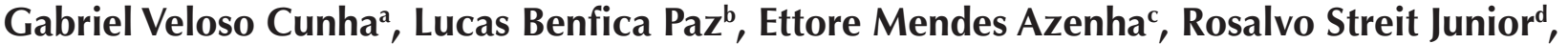 Douglas Araújo dos Santos Albernaz ${ }^{\mathrm{e}}$}

agabrielvelosoc@gmail.com, ${ }^{b}$ lucasbenficaa@gmail.com, ${ }^{\mathrm{c} e t t o r e a z e n h a @ h o t m a i l . c o m, ~}{ }^{\mathrm{d}}$ streitjunior@gmail.com, ${ }^{\mathrm{e}}$ dalbernaz@ucb.br Universidade Católica de Brasília - Brasília (DF), Brasil

Data de recebimento do artigo: 16/08/2017 Data de aceite do artigo: 25/09/2017

\section{RESUMO}

Introdução: Estima-se que há mais de 33 milhóes de casos de aids em todo o mundo. Nesse contexto, algumas parasitoses emergem como problemas de saúde pública, aproveitando-se da suscetibilidade decorrente desse quadro clínico. Objetivos: Elencar e discutir as principais parasitoses oportunistas encontradas em indivíduos portadores de aids, explorando os ciclos de vida de seus agentes, patogenia, manifestaçôes clínicas, prevenção, diagnóstico e tratamento. Métodos: Foram realizadas buscas, sem limites temporais, nas bases de dados virtuais Public Medline (PubMed), Scientific Electronic Library Online (SciELO) e Biblioteca Virtual em Saúde (BVS) a fim de selecionar relatos de caso, boletins epidemiológicos, trabalhos experimentais e revisóes de literatura pertinentes. Resultados: Entre os principais parasitas oportunistas encontrados em pacientes portadores de aids estáo os microsporídios e coccídios como: Isospora belli, Cyclospora sp. e Cryptosporidium sp., para os quais foram realizadas revisóes sistemáticas de literatura neste artigo. Conclusóes: É evidente a imprescindibilidade do desenvolvimento de tratamentos mais eficazes e com menores efeitos adversos, além de uma maior acurácia de diagnóstico por parte dos profissionais de saúde, e rastreamento ambiental pelas instituiçóes competentes.

Palavras-chave: HIV; aids; parasitas oportunistas; protozoários emergentes.

\section{ABSTRACT}

Introduction: It is estimated that there are more than 33 million AIDS cases worldwide. In this sense, some parasitoses has become important public health problems, by taking advantage of the vulnerability due to this clinical condition. Objective: To list and discuss the main opportunistic parasitosis found in individuals with AIDS, exploring the life cycle of their agents, pathogenesis, clinical manifestations, prevention, diagnostic and treatment. Methods: Searches have been conducted, without temporal limits, at the virtual databases Public Medline (PubMed), Scientific Electronic Library Online (SciELO) and Biblioteca Virtual em Saúde (BVS) in order to select case reports, epidemiological bulletins, experimental papers and pertinent literature reviews. Results: Among the main opportunistic parasites found in patients with AIDS there are microsporidia and coccidia such as: Isospora belli, Cyclospora sp. and Cryptosporidium sp., for which a systematic literature review has been performed in this article. Conclusions: It is evident the necessity of developing more efficient treatments with less adverse effects, besides a better diagnostic accuracy by health professionals, and environmental tracking by competent institutions.

Keywords: HIV; AIDS; opportunistic parasites; emerging parasites. 


\section{Introdução}

O continente africano foi sede da primeira epidemia de aids, e sua rápida difusão é associada a complexas relaçôes entre variáveis sociais, culturais e ambientais ${ }^{1}$. Calcula-se que, desde a sua descoberta em 1981, foi causa de óbito de mais de 35 milhóes de pessoas no mundo. Ademais, 33,4 milhóes de pessoas vivem com HIV nos dias atuais, com 3 milhóes de novos infectados por ano ${ }^{2}$.

Nas duas últimas décadas, ocorreram importantes avanços no tratamento e manejo da infecção por HIV, de forma que a estimativa de vida dos infectados pode chegar a 50 anos em países desenvolvidos ${ }^{3}$. As altas taxas de incidência e prevalência, associadas ao aumento da expectativa de vida, tornaram a doença significativa no âmbito da saúde pública ${ }^{4}$. Nesse sentido, é monumental a morbimortalidade relacionada a HIV/aids, e há maior predisposição para determinadas neoplasias ${ }^{5}$, complicaçôes cardiovasculares ${ }^{6}$, ideação suicida ${ }^{7}$ e infecçóes oportunistas ${ }^{7}$.

As infecçóes oportunistas estão entre as principais causas de morbimortalidade nos portadores de aids, especialmente naqueles com baixa contagem de linfócitos CD4, a qual é esperada com o progredir da doença ${ }^{8}$. Organismos que não são patogênicos em indivíduos hígidos se tornaram problemas de saúde pública na medida em que sấo capazes de gerar morbidade na crescente população imunodeprimida ${ }^{9}$.

Nesse viés, é de fundamental importância o conhecimento das manifestaçóes clínicas, do ciclo de vida dos patógenos, da prevenção, do diagnóstico e do tratamento das infecçóes oportunistas, tópicos que serão descritos neste artigo com relação aos principais protozoários entéricos oportunistas no HIV/aids.

As bases teóricas deste trabalho foram obtidas por meio de buscas sem limites temporais nas bases de dados virtuais Public Medline (PubMed), Scientific Electronic Library Online (SciELO) e Biblioteca Virtual em Saúde (BVS). Foram selecionados relatos de caso, boletins epidemiológicos, trabalhos experimentais e revisóes de literatura pertinentes. Evidenciou-se que entre os principais protozoários entéricos oportunistas encontrados em pacientes HIV positivos estão os microsporídios e os coccídios Isospora belli, Cyclospora sp. e Cryptosporidium sp., os quais serão descritos adiante.

\section{Criptosporidiose}

\section{Visão geral}

A criptosporidiose é uma doença causada por protozoários coccídios do gênero Cryptosporidium (filo Apicomplexa ${ }^{10}$. Existem aproximadamente 27 espécies catalogadas do coccídio, das quais Cryptosporidium parvum e Cryptosporidium hominis são as principais causadoras da doença em humanos, sendo transmitidos pela água ou por contato com fezes infectadas ${ }^{11}$.

A primeira descrição foi relatada ${ }^{12}$ no início do século XX - em ratos -, porém somente na década de 1970 foi observada sua relevância em animais ruminantes ${ }^{13}$, bem como foi relatado o primeiro caso de incidência em humanos, intimamente ligado a casos de gastroenterite (1976) ${ }^{14}$. Na década de 1980 , com o advento da aids, a criptosporidiose teve sua ocorrência potencializada, tornando-se altamente prevalente e letal ${ }^{13}$.

A intensidade com que esse parasita afeta o hospedeiro é modulada significativamente pelo estado do seu sistema imunológico. Em pessoas imunocompetentes as manifestaçóes clínicas são mais brandas ${ }^{11}$, enquanto nas imunocomprometidas atua como doença oportunista, causando, entre outros sintomas, diarreia grave (potencialmente letal), especialmente em indivíduos HIV $\operatorname{positivos}^{10}$.

\section{Ciclo de vida}

O ciclo de vida do Cryptosporidium, considerado complexo, compreende estágios assexuados e sexuados de desenvolvimento, realizados em apenas um único hospedeiro ${ }^{11,15}$. A ingestão de alimentos ou água contendo oocistos esporulados - anteriormente disseminados por meio das fezes de indivíduos ou de animais com a doença - é a principal forma de contaminação ${ }^{12}$.

Após sua ingestáo, o oocisto libera quatro esporozoítos por excistação, processo desencadeado pela alteração da temperatura, $\mathrm{pH}$, pela quantidade de dióxido de carbono, pelo auxílio de enzimas pancreáticas, entre outros fatores ${ }^{13}$. Os esporozoítos invadem células da mucosa intestinal, sendo os locais mais afetados o jejuno e íleo ${ }^{10}$. A partir daí, todos os estágios do desenvolvimento ocorrem em um compartimento intracelular extracitoplasmático, com a formação de vacúolos parasitóforos formados a partir da membrana da célula hospedeira ${ }^{11}$.

Dentro da célula há a maturação do esporozoíto em trofozoíto e reprodução assexuada - merogonia ou esquizogonia -, formando os merontes tipo $\mathrm{I}^{15}$. Estes formam oito merozoítos tipo I que são liberados no lúmen, invadem enterócitos vizinhos e podem formar merontes tipo I, reiniciando a merogonia, ou tipo II. Os merontes do tipo II, que produzem até quatro merozoítos, se diferenciam para formar microgametócito e macrogametócito, componentes da fase sexuada do ciclo, os quais, após a fertilização e o período de maturação, darão origem ao zigoto ${ }^{12}$.

Após dois ciclos de esporogonia, o zigoto passa a ser chamado de oocisto, que contém quatro 
esporozoítos ${ }^{11,16}$. Os oocistos podem ser de paredes espessas ou finas. Os primeiros são formas infectantes que são excretadas nas fezes do hospedeiro e permitem a propagaçáo do parasita, uma vez que permanecem viáveis por muitos meses ${ }^{12,16}$. Os de parede fina promovem a autoinfecçáo porque se rompem dentro do organismo do hospedeiro, dando início a um novo ciclo ${ }^{12}$.

O ciclo de vida acima relatado é de difícil replicação em cultura de células, fator que dificulta a análise de várias fases in vitro ${ }^{17}$, bem como o progresso de estudos biológicos, patológicos, imunológicos, moleculares e o teste de novos medicamentos contra o parasita ${ }^{15}$.

\section{Patogenia e quadro clínico}

Como oportunista, a criptosporidiose causa diarreia crônica, caquexia, distúrbios hidroeletrolíticos e perda de peso, fatores que podem resultar na morte de crianças e adultos infectados ${ }^{17}$. Em pessoas HIVpositivas, a criptosporidiose se manifesta quando os níveis de linfócitos TCD4 no sangue estão abaixo de 100 células $/ \mathrm{mm}^{3}$, podendo causar alteraçóes extraintestinais pancreáticas, hepáticas, biliares, bem como nas articulaçóes e no sistema respiratório ${ }^{12}$.

A criptosporidiose respiratória é de difícil diferenciaçáo em relação a outras doenças respiratórias: no trato superior há inflamação das mucosas (nasais, seios, laringe e traqueia), com aumento de secreção nasal e modificaçóes da voz. Já no trato inferior é comum a ocorrência de febre, tosse produtiva, entre outros $^{18}$.

C. parvum e C. hominis são associadas a mais de $90 \%$ das ocorrências de criptosporidiose e, apesar de parecidas, estudos com pessoas HIV-positivas e crianças demonstraram diferenças entre as Cryptosporidium nas manifestaçóes clínicas apresentadas. Relataram-se casos de diarreia, náuseas, vômitos, dores articulares, cefaleia e dor nos olhos causados pela $C$. hominins, em contraste com a C. Parvum, que apresenta somente relatos de ocorrência de diarreia ${ }^{16}$.

\section{Isospora belli}

\section{Visão geral}

A isosporíase é uma das principais doenças oportunistas ligadas ao aumento do número de casos de contaminação pelo HIV. Foi observada pela primeira vez em 1839 e é causada pelo protozoário Isospora belli (do latim: belli, guerra), que foi assim nomeado por ter sido causador da diarreia que afetou as tropas britânicas durante a Primeira Guerra Mundial ${ }^{17}$.
A doença é mais comum em áreas tropicais e subtropicais e pode ser endêmica em algumas regióes da África, do Sudeste Asiático e da América do Sul. O seu aparecimento está diretamente ligado a áreas de saneamento ambiental precário e com péssimas condiçóes de higiene. Esse coccídio, cuja prevalência pode ser de até 15\% em pacientes com HIV na América Central e de até $32 \%$ na América do Sul ${ }^{18}$, causa uma diarreia prolongada em indivíduos imunocomprometidos.

\section{Ciclo de vida}

O ciclo de vida do protozoário começa com a ingestáo de oocistos esporulados, que liberam esporozoítos invasores das células do epitélio intestinal (enterócitos). Estes se multiplicam por endogenia, dando origem ao esquizonte produtor dos merozoítos que rompem as células. A partir daí, a invasão do enterócito acontece por meio de duas etapas ${ }^{19}$. A primeira é a merogonia, quando os merozoítos liberados invadem novas células, repetindo a etapa assexuada (esquizogonia). A segunda é a gamogonia (etapa sexuada), que é marcada pela diferenciação do parasito em microgametas (masculino) e macrogametas (feminino). Os microgametas rompem o enterócito e são liberados no lúmen intestinal, onde nadam até o macrogameta e realizam a fecundação ${ }^{19}$.

$\mathrm{O}$ zigoto transforma-se em oocisto - fase conhecida como esporogonia -, é liberado no lúmen intestinal e, posteriormente, eliminado junto com as fezes do hospedeiro. Esse oocisto amadurece após alguns dias e torna-se infectante no ambiente externo. Eles são muito resistentes e podem permanecer viáveis durante meses, situação que depende das condiçôes de temperatura, umidade e exposição solar ${ }^{19,20}$.

\section{Patogenia e quadro clínico}

O Isospora belli é um enteroparasita causador de uma redução na altura das vilosidades do intestino delgado por meio de uma hiperplasia nas criptas. Consequentemente, o fenômeno é acompanhado por uma diminuição da superfície do intestino delgado. Essa mudança na morfologia das vilosidades é associada com uma reação inflamatória nas células da lâmina própria e dentro do próprio epitélio ${ }^{21}$.

O parasita produz quadros de diarreia aguda autolimitante em indivíduos imunocompetentes, com uma taxa de prevalência que varia entre $0,07 \%$ e $13,10 \%$ dos pacientes com diarreia. Em pacientes imunocomprometidos, a infecção produz uma diarreia prolongada ou crônica grave, marcada pela eliminação das 
formas infectantes do parasita, o que representa um problema de saúde pública. É um parasita frequentemente encontrado em portadores de HIV, o que torna a isosporíase importante para o diagnóstico da aids ${ }^{17}$.

A infecção pode ser assintomática ou oligossintomática. Os pacientes com a imunidade debilitada, caso dos portadores de HIV, por exemplo, podem apresentar um quadro diarreico de aparição brusca, acompanhado de dor abdominal, fezes meteóricas, náuseas, febre e mal-estar. As fezes são pastosas ou líquidas e muito frequentes (até 10 evacuaçōes diárias) ${ }^{21}$. A diarreia causada pelo $I$. belli é, na maioria dos casos, muito fluida, secretória e prolongada, o que pode conduzir o paciente a um quadro de desidratação que requer hospitalização. Febre e perda de peso são outros sintomas característicos. Também pode causar vomito e cefaleia $^{22,23}$

\section{Cyclospora cayetanesis}

\section{Introdução}

Na literatura médica, os primeiros casos de infecçóes ocorridas por ciclosporíase foram relatados no ano de $1979^{23}$. Esse coccídio intestinal é caracterizado por ocasionar: diarreia aguda e prolongada em vítimas imunocompetentes, diarreia crônica em pessoas imunocomprometidas e a diarreia do viajante ${ }^{20}$.

Atualmente, essa parasitose tem ganhado visibilidade no meio científico. A associação com uma doença famosa e a exacerbação no quadro clínico têm reforçado a sua importância. A ciclosporíase ganhou notoriedade na década de 1980, período em que a epidemia de aids sobreveio. Os sintomas dessa parasitose relacionados aos portadores de HIV são mais significativos e intensos que nos não portadores ${ }^{24}$.

A infecção por Cyclospora está relacionada também à facilidade de disseminação. Pessoas que realizam viagens com destino a áreas endêmicas, se contaminadas, atuam como vetores dessa enfermidade quando voltam ao seu lugar de origem ${ }^{25}$. Sabe-se, porém, que a sua distribuição é global, mas com prevalência nas regiōes tropicais e subtropicais ${ }^{23}$.

Na América do Norte (Estados Unidos e Canadá) surgiu um dos maiores surtos já relatados: em meados da década de 1990 foram documentados 177 surtos em uma amostra de 3.500 pessoas. No Peru, de 6 a $18 \%$ das crianças que apresentam diarreia aguda são contaminados por $C$. cayetanensis; na zona rural da Venezuela, 5,3\%; em Cuba, 4,4\%; no Nepal são $4,8 \%$ e na Tanzânia $2,5 \%$ das crianças recebem esse diagnóstico ${ }^{23}$.
No Brasil, especificamente em São Paulo, relatos demonstram que de $0,3 \%$ a $0,7 \%$ dos pacientes são diagnosticados com a parasitose. Essa patologia não possui dados constantes e, por isso, não é previsível, mas sabe-se que difere entre regióes devido a fatores ambientais, como umidade e temperatura, que tornam algumas áreas propícias para a ciclosporíase e outras nem tanto ${ }^{23}$

\section{Ciclo de vida}

O ciclo de vida do Cyclospora cayetanesis é composto por várias etapas. A primeira se inicia quando o paciente infectado elimina oocistos em suas fezes, que precisam de alguns dias e condiçóes ideais para que ocorra a esporulação com êxito. Depois de ingeridos, ocorre o desencistamento dos oocistos esporulados, liberando esporozoítos no duodeno e jejuno. No momento em que estes infectam as células do tecido epitelial intestinal acontece a transformação de esporozoíto em trofozoíto ${ }^{24}$.

A segunda etapa é marcada pelo processo de divisão celular assexuada chamada merogonia, no qual os trofozoítos formarão os merontes, que sáo constituídos pelos merozoítos. Assim que estes se rompem dos merontes começam a infectar células diversas, iniciando uma nova fase.

A terceira etapa corresponde à diferenciação sexual: a forma masculina (microgametócito) produz microgametas flagelados e a feminina (macrogametócito) fica à espera de ser fertilizada. Quando isso ocorre, há formação do zigoto, o qual possui uma parede grossa e resistente após o desenvolvimento, o que o torna um oocisto e, posteriormente, esporulado, podendo perdurar por um grande período no ambiente e, mesmo com condiçôes desfavoráveis, continuar apto a infectar ${ }^{26}$.

\section{Patogenia e quadro clínico}

Essa infecção é marcada pela inflamação da lâmina própria, atrofia das vilosidades, hiperplasia das criptas e aumento expressivo das células plasmáticas e dos linfócitos intraepiteliais ${ }^{27}$. Em paciente imunocompetente o quadro diarreico é efêmero, associado com vômitos, mal-estar, febre baixa, mialgia, fadiga e perda de peso. Em pacientes imunocomprometidos, os sintomas são os mesmos, todavia com uma diarreia mais prolongada. Nesses hospedeiros mais vulneráveis, há também relatos de que essa infecçáo influencia em doenças biliares ${ }^{26}$. 


\section{Microsporidia}

\section{Visão geral}

O termo microsporidia diz respeito a um filo de parasitas intracelulares obrigatórios que recentemente foram classificados como fungos ${ }^{28}$. Hoje são reconhecidas mais de 1.400 espécies, agrupadas em aproximadamente 160 gêneros, muitas com importância na agricultura, veterinária e ciências médicas, das quais se sabe que 14 espécies infectam humanos ${ }^{29}$.

A microsporidiose é uma doença emergente e com alta prevalência, sendo cada vez mais relatada ao redor do mundo em um vasto rol de populaçóes humanas ${ }^{30}$. Os microsporídios foram inicialmente estudados devido à sua importância econômica, uma vez que estão associados a infecçôes em bichos-da-seda, abelhas, peixes e animais de fazenda. Historicamente também foram relacionados a interferências em pesquisas biomédicas, por causarem infecçóes subclínicas em animais de laboratório ${ }^{21,31,32}$.

Eram raramente reconhecidos como causadores de doenças em humanos antes da pandemia da aids ${ }^{32}$. Embora os portadores não sejam os únicos infectados, as manifestaçóes clínicas são menos frequentes em imunocompetentes ${ }^{28,33}$. Sua prevalência em portadores de HIV é próxima a $15 \%^{32}$. São importantes agentes infecciosos também em receptores de órgãos e portadores de doenças autoimunes em terapia de imunossupressão, pacientes oncológicos durante quimioterapia, crianças, idosos e viajantes ${ }^{32}$.

\section{Ciclo de vida}

Os microsporídios não possuem estágios de vida ativa fora das células hospedeiras ${ }^{34}$. Sua forma infecciosa é o esporo, o qual é extremamente resistente no meio e pode sobreviver, a depender da espécie, por até mais que 12 meses $^{30,32}$. Yazar et al. classificaram o ciclo de vida dos microsporídios em três fases: fase infectiva ou ambiental, fase proliferativa e fase formadora de esporos $^{35}$.

Os esporos que infectam humanos são ovais e relativamente pequenos $(1,0-3,0 \mu \mathrm{m}$ por $1,5-4,0 \mu \mathrm{m})$. Quando maduros apresentam um complexo de Golgi atípico - denominado polaroplasto - e um disco de ancoragem $^{30}$. Há uma estrutura tubular oca que vai do disco de ancoragem à regiáo média-posterior do esporo, denominada filamento polar ou tubo polar ${ }^{30,34}$.

Com alteraçóes no $\mathrm{pH}$ e na pressão osmótica, o polaroplasto e o disco de ancoragem se edemaciam, de forma a expulsar os conteúdos intracelulares do esporo para a célula hospedeira por meio do filamento polar, processo que ocorre em menos de dois segundos ${ }^{30,32,34}$. Após a penetração, o material introduzido é revestido por uma nova membrana advinda do polaroplasto. Outro mecanismo discutido na literatura, mas ainda não bem compreendido, é a entrada do parasita por meio de fagocitose ${ }^{34}$.

Ocorre a germinaçáo, um processo molecularmente ainda não bem elucidado, mas que acontece em contato direto com o citoplasma da célula hospedeira ${ }^{34}$. Posteriormente, o parasita se multiplica por merogonia e forma seus esporos por esporogonia ${ }^{30}$.

O Enterocytozoon bieneusi é a espécie mais relatada em infecçóes humanas ${ }^{30}$. Habitualmente infecta o trato biliar e o intestino delgado, especialmente duodeno e jejuno, de forma que os esporos maduros são liberados pelas fezes ${ }^{28}$. Microsporídios menos frequentes, como o gênero Encephalitozoon, geralmente não ficam restritos ao trato gastrointestinal com o progredir da infecção, chegando aos rins e trato respiratório, explicando achados como esporos na urina e secreçóes respiratórias ${ }^{30}$.

O local onde a infecção ocorrerá majoritariamente depende da via de transmissão: geralmente são células epiteliais de revestimento do trato gastrointestinal ou aparelho respiratório, fato atribuído à predominância da ingestão e inalaçáo de esporos como mecanismo de contaminação ${ }^{28,30}$. Não há relatos de propagação vertical por via transplacentária em humanos, mas é conhecido que ocorre em diversos mamíferos, incluindo primatas não humanos ${ }^{30}$. A transmissão também está associada ao consumo de água não filtrada e nado em ambientes em contato com reservatórios animais ${ }^{30,33,35}$.

\section{Patogenia e quadro clínico}

As manifestações clínicas não ocorrem exclusivamente em portadores de aids, embora o curso da infecção seja dependente do estado imunológico do hospedeiro $^{35}$. O quadro em imunocompetentes geralmente é assintomático ou clinicamente brando, sendo mais relatada diarreia aguda e autolimitada ${ }^{30,36}$. Imunodeprimidos estão mais propensos a desenvolver sintomatologia séria e potencialmente fatal ${ }^{1,7,9}$.

Portadores de aids infectados, geralmente por E. bieneusi e. intestinalis, e com contagem sérica de células TCD $4<100 / \mathrm{ml}$ frequentemente desenvolvem diarreia crônica, má absorção intestinal, perda de apetite, perda de peso, dor abdominal e febre ${ }^{30,32}$. Infecçóes associadas a espécies de Encephalitozoon, Trachipleistophora e Pleistophora estão relacionadas com encefalite, sinusite, nefrite, miosite, peritonite, ceratite, e pneumonia ${ }^{35,37}$. 
As espécies $E$. bieneusi e. intestinalis infectam as células epiteliais das vilosidades do intestino delgado, principalmente duodeno e jejuno, levando à atrofia dessas estruturas e hiperplasia das criptas. A redução da área de contato da mucosa contribui para a má absorçáo, assim como na criptosporidiose ${ }^{32}$.

Casos associados a microsporídios envolvendo abcessos cerebrais, endocardite e osteomielite também foram descritos, sendo que a ocorrência da forma disseminada (extraintestinal) determina um pior prognóstico ${ }^{36}$.

Manifestaçóes oculares podem se apresentar de forma isolada ou como componente de uma infecção sistêmica. O acometimento oftalmológico usualmente se dá com ceratoconjuntivite superficial ou ceratite. Esta pode ocorrer, em pacientes previamente hígidos, de forma clinicamente semelhante à ceratite herpética, com histórico de vermelhidão, dor, fotofobia e decréscimo da acuidade visual, sendo um importante diagnóstico diferencial ${ }^{38}$.

\section{Prevenção}

A microsporidiose é um problema de saúde pública no âmbito sanitário, uma vez que espécies que infectam humanos já foram descritas em fontes de água e em uma série de animais que vivem em proximidade com o homem ${ }^{30,33,37}$.

Indivíduos imunocompetentes assintomaticamente infectados podem, de forma contínua, liberar esporos pelas fezes e urina, sendo importantes reservatórios do parasita ${ }^{32,33}$. A transmissão ocorre principalmente pela via fecal-oral, mas também por meio de inalação, lesões na pele/mucosas e contato sexual. As fontes de infecçôes são predominantemente humanos, outros animais, água e alimentos com espécies do parasita ${ }^{37}$.

Microsporídios podem ser uma causa subestimada de surtos de doenças gastrointestinais, devendo ser explorados como possíveis agentes causadores de infecçóes através da água e alimentos. São poucos os registros de epidemias devidas ao filo em questáo ${ }^{28}$. Decraene et al. relataram um dos raros surtos atribuídos à microsporidiose em um hotel na Suécia, associado a alimentos contaminados com Enterocytozoon bieneusi ${ }^{39}$.

Diversos patógenos, tais como Microsporídios, Giardia e Cryptosporidium são frequentemente transmitidos por meio da água, sendo que a sua contaminação pode indicar a presença de reservatórios no ambiente. Izquierdo et al. encontraram esporos de microsporídios em diversas estaçôes de tratamento de água potável, esgoto e em rios de áreas recreacionais na Espanha, divulgando um dos primeiros trabalhos com tal ênfase.
Demonstra-se a necessidade de estudos mais abrangentes a fim de direcionar políticas públicas de saúde com esse viés ${ }^{33}$.

\section{Diagnóstico da microsporidia}

Em cerca de $50 \%$ dos casos de diarreia o agente etiológico não é determinado, sendo provável que os microsporídios contribuam para esse número, uma vez que são de difícil suspeição clínica e técnicas de busca específicas dificilmente são empregadas ${ }^{32}$.

Métodos diagnósticos de alta eficácia foram desenvolvidos, entretanto demandam recursos pessoais e equipamentos que não estão disponíveis em quaisquer laboratórios. Na prática, o diagnóstico acaba sendo feito por meio da busca por esporos em fezes, urina e secreçóes do trato respiratório por meio de microscopia ópti$\mathrm{ca}$, técnica que não fornece informaçóes como gênero e espécie do microsporídio ${ }^{28,36}$.

O diagnóstico por métodos convencionais é desafiador, se fazendo necessário para um bom manejo clínico que haja artefatos como um microscópio eletrônico e técnicas moleculares como reação em cadeia da polimerase (PCR) e testes sorológicos ${ }^{38}$. Nos casos de infecçôes intestinais, o diagnóstico também pode ser feito por meio de biópsias do intestino delgado ${ }^{28}$.

São organismos de difícil cultura, dificultando a obtenção de quantidades razoáveis de antígenos para testes sorológicos, que devido aos avanços tecnológicos têm se tornado cada vez mais eficazes para o diagnóstico de imunocompetentes ${ }^{38}$. O diagnóstico definitivo e específico ainda é dado por meio da observação de esporos por microscopia eletrônica, na qual a identificação é feita predominantemente pela visualização do filamento polar ${ }^{30}$.

\section{Diagnóstico de Cryptosporidium parvum, Isospora belli e Cyclospora cayetanensis}

A detecção de coccídios como os de I. belli é dificultada pelo tamanho reduzido dos esporos e pela semelhança com outros microrganismos ${ }^{40}$. Para a ciclosporíase, a microscopia óptica é uma possibilidade diagnóstica, sendo mais utilizada que os métodos moleculares pois, embora estes sejam mais sensíveis, são também menos acessíveis $^{25}$. Nesse contexto se destacam também as coloraçôes fluorescentes e a PCR para o diagnóstico de $I$. belli, mas com uso limitado na prática pelos seus custos relativamente altos ${ }^{40}$. A PCR também pode confirmar o diagnóstico de criptosporidiose ${ }^{16}$.

O exame coproparasitológico é um importante artifício diagnóstico para as três parasitoses. $\mathrm{Na}$ isosporíase, os oocistos começam a aparecer nas fezes de uma a duas 
semanas após a infecção, podendo ser de difícil visualização devido à pequena quantidade que é eliminada ${ }^{19}$. A pesquisa laboratorial é fundamental para a identificação da criptosporidiose ${ }^{16}$, podendo ser feita não somente a partir de amostras de fezes, mas também de fluidos corporais $^{12}$.

Em uma comparação entre os métodos de ZiehlNielsen modificado (ZNm) e Acid-Fast-Trichrome (AFT), concluiu-se que o método mais indicado é o $\mathrm{ZNm}$, tanto para o diagnóstico de isosporíase como de criptosporíase, principalmente quando esse método é associado ao procedimento de centrifugação-concentração ${ }^{41}$. Para a ciclosporíase são utilizados Ziehl-Neelsen modificado ou Kinyoun ${ }^{19}$, uma vez que técnicas comuns como Giemsa, trichrome e Gram-chromotrope não têm eficácia para o diagnóstico de Cyclospora ${ }^{21}$. A eficácia diagnóstica depende da utilização de coloração de qualidade e da habilidade visual do profissional ${ }^{42}$.

\section{Tratamento das principais parasitoses associadas à aids}

Até o momento não existem relatos na literatura de abordagens terapêuticas eficazes para o tratamento da criptosporidiose humana. Macrolídeos, paromicina e nitazoxanida já foram testados, porém demonstraram apenas uma reduçáo da gravidade da doença em indivíduos imunocompetentes ${ }^{43}$. A nitazoxanida é o único medicamento aprovado pelo Food and Drug Administration (FDA) para o tratamento da criptosporidiose e, mesmo quando usado em altas doses e por períodos prolongados, ainda é ineficaz em HIV positi$\operatorname{vos}^{14}$. A melhora imunológica advinda da terapia antirretroviral continua a ser a melhor expectativa ${ }^{14,42,43}$.

A trimetoprima associada a sulfonamidas é de eficiência comprovada na abordagem da isosporíase. A combinação da trimetoprima com o sulfametoxazol, conhecida como cotrimoxazol, é uma das mais recomendadas. Essa combinaçáo age ao inibir a síntese de ácidos nucléicos do parasita. É uma importante opção terapêutica pela sua alta disponibilidade e seu baixo custo $^{19}$. A dosagem varia de acordo com a imunocompetência do paciente - caso seja baixa, se fazem necessárias doses mais altas com maior frequência, além de uma terapia de manutenção. As principais complicaçóes dessa terapia são as reaçóes alérgicas que podem acontecer em resposta ao uso das sulfonamidas, como nefrotoxicidade e anemia ${ }^{19}$.

O tratamento indicado para infectados pelo Cyclospora cayetanesis é o uso dos fármacos trimetoprim e sulfametoxazol. Imunocomprometidos sofrem com a duração e a dosagem dos medicamentos, que são maiores se comparadas às dos imunocompetentes com a mesma enfermidade ${ }^{26}$.

A primeira droga de escolha para tratar a maioria das espécies do filo microsporidia é o Albendazol, que, embora tenha eficácia limitada contra o $E$. bieneuzi, é altamente eficaz contra espécies de Encephalitozoon ${ }^{30,32}$. O Fumagillin é utilizado contra E. bieneusi e existem relatos de sua eficácia no manejo de infecções oculares, entretanto o seu uso é limitado devido à toxicidade para a medula óssea, sendo altamente necessário o desenvolvimento de drogas com menores efeitos adversos ${ }^{30,37}$. A melhora da resposta imunológica advinda do tratamento antirretroviral proporciona uma importante melhora do quadro ${ }^{36}$.

\section{Comentários}

É conhecido que imunodeficiências levam a um considerável aumento da susceptibilidade a infecçóes. $\mathrm{O}$ vírus HIV leva a uma diminuição progressiva de linfócitos T CD4 e afeta a função de células dendríticas e macrófagos, prejudicando a resposta imunológica e fazendo com que as infecçóes oportunistas se tornem causas importantes de óbitos. Deve-se considerar ainda a cronicidade da infecçáo, uma vez que a resposta imune adaptativa gerada contra o vírus raramente o elimina, além de que a terapia antirretroviral (HAART) não possui eficácia absoluta ${ }^{44}$.

Os patógenos descritos neste trabalho somente receberam notoriedade após a pandemia da aids, de forma que - cada um com as suas especificidades - não seriam importantes problemas de saúde pública como o são hoje caso houvesse o devido controle e a difusão do tratamento da infecção pelo $\mathrm{HIV}^{12,14,25,32}$. A terapia antirretroviral, além de reduzir de forma importante a morbimortalidade no grupo imunodeficiente por meio de rápida redução da viremia, chegando a níveis próximos ao limite de detecção, proporciona um aumento lento, mas constante, do índice de linfócitos $\mathrm{CD} 4^{44}$. Essa melhora é suficiente para reestabelecer a imunidade contra infecçóes oportunistas ${ }^{45}$.

Nas últimas décadas foram realizados grandes avanços na elucidação de diversas variáveis associadas às infecçóes oportunistas em questão, mas ainda existem diversos desafios a serem superados, tais como o detalhamento dos seus mecanismos imunológicos ${ }^{42}$, a elaboração de métodos diagnósticos mais eficazes devido à inespecificidade dos seus sintomas ${ }^{46}$, bem como a elaboração de medidas intervencionistas na saúde pública.

Prevenir as infecções oportunistas é uma tarefa árdua, uma vez que é significativa a taxa de transmissão e resistência dos seus agentes ${ }^{14,15,20,30}$, porém é uma atitude de extrema importância, especialmente ao se levar 
em conta a inexistência de vacina ou de antiparasitários eficazes e com baixos efeitos adversos. A melhor estratégia ainda é a prevenção, pois a HAART não é aplicável a muitos indivíduos devido aos seus custos e efeitos secundários ao tratamento ${ }^{44}$.

O barateamento dos métodos de detecção e sequenciamento genômico é uma realidade que trará grandes benefícios no estudo dessas infecçóes, auxiliando na compreensão de parasitas específicos ${ }^{13}$. Maus hábitos de higiene também são fatores associados, especialmente para o Cyclospora cayetanesis, cuja disseminação reflete diretamente esse fator de risco, uma vez que não é transmitido entre pessoas pois seus oocistos exigem vários dias fora do hospedeiro para se tornarem infecciosos. Não são conhecidos outros reservatórios naturais além do homem, aumentando, assim, o fardo da responsabilidade de erradicar esse parasita ${ }^{47,48}$.

Torna-se evidente que a prevalência das principais parasitoses oportunistas associadas à aids somente será reduzida a partir do momento em que técnicas específicas para a sua detecção passarem a ser empregadas rotineiramente, tanto no âmbito clínico-laboratorial quanto como medida de saúde pública. Os poucos dados estatísticos disponíveis acerca da sua prevalência refletem a pouca importância que tem sido dada às infecçóes dessa natureza. Estima-se que haja uma melhoria da situação geral com o barateamento dos métodos diagnósticos e o desenvolvimento de fármacos mais eficazes com menores efeitos adversos, sendo necessárias ações conjuntas de políticas governamentais com o auxílio populacional para se atingir um contexto ideal.

\section{Referências}

1. Lewis DA. Review of the book A history of the African AIDS epidemic. Sex Transm Infect. 2006;82(3):266.

2. Biswas MHA. AIDS epidemic worldwide and the millennium development strategies: a light for lives. HIV AIDS Rev. 2012;11(4):87-94.

3. Lawn SD, Török ME, Wood R. Optimum time to start antiretroviral therapy during HIV-associated opportunistic infections. Curr Opin Infect Dis. 2011;24(1):34-42.

4. Smith E. Dawning answers: how the HIV/AIDS epidemic has helped to strengthen public health. J Epidemiol Community Health. 2004;58(4):355.

5. Bonnet F, Chêne G. Evolving epidemiology of malignancies in HIV. Curr Opin Oncol. 2008;20(5):534-40.

6. Feinstein MJ, Bogorodskaya M, Bloomfield GS, Vendanthan R, Siedner MJ, Kwan GF, et al. Cardiovascular complications of HIV in endemic countries. Curr Cardiol Rep. 2016;18(11):113.

7. Bitew H, Andargie G, Tadesse A, Belete A, Fekadu W, Mekonen T. Suicidal ideation, attempt, and determining factors among HIV/AIDS patients, Ethiopia. Depress Res Treat. 2016;2016:8913160.

8. Caceres NA, Vieira MMC, Vieira IF, Monteleone VF, Moreira Neto LJ, Bonafe S. Opportunistic infections in AIDS patients. Arch Med. 2015;7(5):1-17.

9. Sandhu A, Samra AK. Opportunistic infections and disease implications in HIV/AIDS. Int J Pharm Sci Invent. 2013;2(5):47-54.

10. Benamrouz S, Conseil V, Creusy C, Calderon E, Dei-Cas E, Certad G. Parasites and malignancies, a review, with emphasis on digestive cancer induced by Cryptosporidium parvum (Alveolata: Apicomplexa). Parasite. 2012;19(2):101-15.

11. O'Hara SP, Chen XM. The cell biology of cryptosporidium infection. Microbes Infect. 2011;13(8-9):721-30.

12. Ferreira MS, Borges AS. Some aspects of protozoan infections in immunocompromised patients: a review. Mem Inst Oswaldo Cruz. 2002;97(4):443-57.

13. Widmer G, Sullivan S. Genomics and population biology of Cryptosporidium species. Parasite Immunol. 2012;34(2-3):61-71.

14. Shirley DA, Moonah SN, Kotloff KL. Burden of disease from cryptosporidiosis. Curr Opin Infect Dis. 2012;25(5):555-63.

15. Ryan U, Hijjawi N. New developments in Cryptosporidium research. Int J Parasitol. 2015;45(6):367-73.

16. Bouzid M, Hunter PR, Chalmers RM, Tyler KM. Cryptosporidium pathogenicity and virulence. Clin Microbiol Rev. 2013;26(1):115-34.

17. Assis DC, Resende DV, Cabrine-Santos M, Correia D, Oliveira-Silva MB. Prevalence and genetic characterization of Cryptosporidium spp. and Cystoisospora belli in HIV-infected patients. Rev Inst Med Trop Sao Paulo. 2013;55(3):149-54.

18. Sponseller JK, Griffiths JK, Tzipori S. The evolution of respiratory Cryptosporidiosis: evidence for transmission by inhalation. Clin Microbiol Rev. 2014;27(3):575-86.

19. Patricia Neira O, Elizabeth Barthel M, Gonzalo Wilson L, Nelson Muñoz S. Infección por Isospora belli en pacientes coninfección por VIH. Presentación de dos casos y revisión de la literatura. Rev Chil Infect. 2010;27(3):219-27.

20. Lindsay DS, Dubey JP, Blagburn BL. Biology of Isospora spp. from humans, nonhuman primates, and domestic animals. Clin Microbiol Rev. 1997;10(1):19-34.

21. Frenkel JK, Silva MB, Saldanha JC, Silva-Vergara ML, Correia D, Barata $\mathrm{CH}$, et al. Extraintestinal finding of Isospora belli unizoic cysts in a patient with AIDS: case report. Rev Soc Bras Med Trop. 2003;36(3):409-12.

22. Yazar S, Yalcln S, Sahin Í. Human cyclosporiosis in Turkey. World J Gastroenterol. 2004;10(12):1844-47.

23. Mezzari A, Antunes HBB, Wiebbelling AMP. Cyclospora cayetanensis, um novo protozoário a ser pesquisado. Rev Ass Med Brasil. 1999;45(4):347-8.

24. Ortega YR, Sanchez R. Update on Cyclospora cayetanensis, a food-borne and waterborne parasite. Clin Microbiol Rev. 2010;23(1):218-34. 
25. Chawla R, Ichhpujani RL. Enteric spore-forming opportunistic parasites in HIV/AIDS. Trop Parasitol. 2011;1(1):15-9.

26. Arora DR, Arora B. AIDS - associated parasitic diarrhoea. Indian J Med Microbiol. 2009;27(3):185-90.

27. Weitz Vattuone JC, Carolina Weitz R, Marilena Canales R, Ruy Moya R. Infección por Cyclospora cayetanensis: revisión a propósito de tres casos de diarrea del viajero. Rev Chil Infectol. 2009;26(6):549-54.

28. Field AS, Milner Junior DA. Intestinal microsporidiosis. Clin Lab Med. 2015;35(2):445-59.

29. Ghosh K, Weiss LM. T cell response and persistence of the microsporidia. FEMS Microbiol Rev. 2012;36(3):748-60.

30. Didier ES, Stovall ME, Green LC, Brindley PJ, Sestak K, Didier PJ. Epidemiology of microsporidiosis: sources and modes of transmission. Vet Parasitol. 2004;126(1-2):145-66.

31. Saharia KK, Koup RA. T cell susceptibility to HIV influences outcome of opportunisticinfections. Cell. 2013;155(3):505-14.

32. Didier ES, Weiss LM. Microsporidiosis: not just in AIDS patients. Curr Opin Infect Dis. 2011;24(5):490-5.

33. Izquierdo F, Castro Hermida JA, Fenoy S, Mezo M, González-Warleta M, Aguila C. Detection of microsporidia in drinking water, wastewater and recreational rivers. Water Res. 2011;45(16):4837-43.

34. Franzen C. Microsporidia: how can they invade other cells? Trends Parasitol. 2004;20(6):275-9.

35. Yazar S, Koru Ö, Hamamci B, Çetinkaya Ü, Karaman Ü, Kuk S. Mikrosporidialar ve Mikrosporidiyozis. Turkiye Parazitol Derg. 2013;37:123-34.

36. Ramanan P, Pritt BS. Extraintestinal microsporidiosis. J Clin Microbiol. 2014;52(11):3839-44.

37. Anane S, Attouchi H. Microsporidiosis: epidemiology, clinical data and therapy. Gastroenterol Clin Biol. 2010;34(8-9):450-64.

38. Alkatan HM, Al-Zaaidi S, Athmanathan S. Microsporidial keratitis: literature review and report of 2 cases in a tertiary eye care center. Saudi J Ophthalmol. 2012;26(2):199-203.
39. Decraene V, Lebbad M, Botero-Kleiven S, Gustavsson A-M, Löfdahl M. First reported foodborne outbreak associated with microsporidia, Sweden, October 2009. Epidemiol Infect. 2012;140(3):519-27.

40. Rivero-Rodríguez Z, Hernández A, Bracho Á, Salazar S, Villalobos R. Prevalencia de microsporidios intestinales y otros enteroparásitos en pacientes con VIH positivo de Maracaibo, Venezuela. Biomed. 2013;33(4):538-45.

41. Rigo CR, Franco RMB. Comparison between the modified Ziehl-Neelsen and Acid-Fast-Trichrome methods for fecal screening of Cryptosporidium parvum and Isospora belli. Rev Soc Bras Med Trop. 2002;35(3):209-14.

42. Checkley W, White Junior AC, Jaganath D, Arrowood MJ, Chalmers RM, Chen XM, et al. A review of the global burden, novel diagnostics, therapeutics, and vaccine targets for cryptosporidium. Lancet Infect Dis. 2015;15(1):85-94.

43. Chako CZ, Tyler JW, Schultz LG, Chiguma L, Beernsten BT. Cryptosporidiosis in people: it's not just about the cows. J Vet Intern Med. 2010;24(1):37-43.

44. Murphy K, Travers P, Walport M. Imunobiologia de Janeway. Porto Alegre: Artmed, 2010.

45. Lodi S, Del Amo J, Moreno S, Bucher HC, Furrer H, Logan R, et al. Opportunistic infections and AIDS malignancies early after initiating combination antiretroviral therapy in high-income countries. AIDS. 2014;28(16):2461-73.

46. Sancak B, Akyon Y, Ergüven S. Cyclospora infection in five immunocompetent patients in a Turkish university hospital. J Med Microbiol. 2006;55(Pt 4):459-62.

47. Chacín-Bonilla L. Cyclospora cayetanensis as a global health problem. Epidemiol. 2012;2(3):e110.

48. desVignes-Kendrick M, Reynolds K, Lee T, Gaul L, Klein K, Irvin K, et al. Notes from the field: outbreaks of Cyclosporiasis - United States, June-August 2013. Centers for Disease Control and Prevention Morb. Mortal. Wkly. Rep (MMWR). 2013;62(43):862.

\section{Como citar este artigo:}

Cunha GV, Paz LB, Azenha EM, Streit Junior R, Albernaz DAS. Principais protozoários entéricos oportunistas associados à aids: Cryptosporidium parvum, Isospora belli, Cyclospora cayetanensis e microsporidia. Rev. Aten. Saúde. 2018;16(55):99-107. 